\title{
Action painting, happening e performance art: da ação como fator significante à ação como obra nas artes visuais ${ }^{1}$
}

\author{
FERNANDO CESAR RIBEIRO
}

Resumo

A ação foi inserida como elemento significante nas artes visuais pela action painting, expressa por meio do trabalho de artistas como Jackson Pollock e também pelo trabalho teórico de Harold Rosenberg. Mediante a filosofia da ação de Paul Ricoeur, focada principalmente na rede conceitual ação, uma análise precisa da compreensão da ação permitirá um estudo específico desta nas artes visuais. Nesse sentido, são investigados três momentos: a action painting, como inserção da ação na obra de arte; a ação com intenção de acontecimento natural, no happening; e a ação como obra, na performance art.

Palavras-chave:

Action painting, happening, performance art 


\title{
Action painting, happening and performance art from the action as significantfactorto the action as work in the visual arts
}

FERNANDO CESAR RIBEIRO

\begin{abstract}
The action was inserted as a significant element in visual arts by action painting, expressed through the work of artists such as Jackson Pollock and also by the theoretical work of Harold Rosenberg. Through Paul Ricoeur's philosophy of action, with its main focus on conceptual framework of action, a precise analysis of the comprehension of action allows us to make a specific study about the action itself in visual arts. Following this line of thought, there are three distinguished moments: action painting, as an insertion of action in the work of art; in happening, the action with the intention of being something that happens naturally; and the action itself as a work of art, in performance art.
\end{abstract}

Keywords: Action painting, happening, performance art 


\section{Introdução}

O seguinte trabalho se propõe a uma análise da ação nas artes visuais, tomando-a como elemento significante da obra de arte, tendo em vista a filosofia da ação de Paul Ricoeur. Para tal desenvolvimento, foram feitos dois recortes pontuais: em relação à filosofia da ação e à história da arte.

O primeiro recorte se refere à filosofia da ação de Paul Ricoeur. O desenvolvimento dessa filosofia surge do entrelaçamento entre a teoria da ação ${ }^{2}$ desenvolvida pelos filósofos analíticos de língua inglesa com a fenomenologia e a hermenêutica. Essa filosofia está dispersa em toda sua produção e não será o caso aqui de abarcá-la totalmente, por fugir deste empreendimento. Portanto, o foco desta análise estará no desenvolvimento e reflexões do autor no que tange à semântica da ação, relacionada à essa teoria da ação. Como Ricoeur (1988, p. 11) explicita "a tarefa da análise conceptual consistirá em elaborar as noções primeiras ou categorias sem as quais seria impossível dar à acção o seu sentido de acção".

A semântica da ação, junto com a pragmática da ação, fazem parte de um primeiro estágio na filosofia da ação de Paul Ricoeur: a descrição da ação. Os estágios subsequentes são os que se referem ao narrar e ao prescrever. Em O Discurso da Acção, obra voltada principalmente a esse primeiro estágio, Ricoeur reforça que existe uma especificidade da ação a ser estudada pela filosofia, diferentemente das ciências humanas, assim como da ética. O seu projeto se apóia na descrição da ação e na "análise dos discursos em que o homem diz o seu fazer, abstraindo do louvor e da censura pelos quais qualifica o seu fazer em termos de moralidade" (RICOEUR, 1988, p. 11).

O desenvolvimento de sua filosofia, a partir destas duas áreas específicas, permite a ele um estudo da ação como um 
campo prévio aos da ética, política e jurídica. A conexão com esses outros campos estaria relacionada a uma mediação da narrativa, que direciona a prescrição. Contudo, antes de se verificar as imputações dessas áreas na ação, é do interesse de Ricoeur o estudo da ação mesma, tendo como âncora a sua descrição por meio da linguagem. Em suas palavras:

Em vez de nos entregarmos a uma intuição das essências do vivido, apreendidas em exemplos singulares bem escolhidos, apoiamo-nos na codificação da experiência no seu dizer e contamos com a notável propriedade da linguagem não só de articular a experiência, mas de conservar, graças a uma espécie de seleção natural, as expressões mais aptas, as distinções subtis mais apropriadas às circunstâncias do agir humano. (RICOEUR, 1988, p. 12-13)

Desta maneira, delineiam-se alguns conceitos para a definição da ação que Ricoeur toma emprestado da teoria da ação desenvolvida por filósofos como A. I. Melden, E. Ancombe, A. Danto e R. Taylor. Esse empréstimo não é necessariamente uma dívida com essa filosofia, pois ele reconhece os limites da teoria da ação desenvolvida pelos analíticos. E, em sua filosofia da ação, propõe a superação desses limites por intermédio da fenomenologia, antes, e da hermenêutica, posteriormente.

O principal conceito no qual Paul Ricoeur se apóia e sempre faz referência, ao cruzar entre as mais diversas filosofias, é a rede conceitual da ação. A ação, considerada como "aquilo que alguém faz", é parte de uma rede que inclui outros diversos conceitos, como agentes, "circunstâncias, intenções, motivos, deliberações, moção voluntária ou involuntária, passividade, constrangimento, resultados desejados etc." (RICOEUR, 1991, p. 75). Todos esses conceitos estão diretamente interligados e são dependentes da própria rede. Compreender sentido e significado de cada termo está relacionado a compreender a inter-significação entre eles e o sentido da própria rede. Segundo o autor, um modo eficaz de identificar toda a rede está nas questões que podem ser levantadas a respeito dela, tais como "Quem?”, “Quê?", "Por quê?”, “Como?”, “Onde?”, “Quando?”.

Em vista disso, Ricoeur faz referência sempre a essas questões para a sua análise. Em sua filosofia da ação, a importância de toda essa rede encontra-se na relação entre o "quem?" e o "o quê?" da ação, ou seja, na relação entre agente e ação. A sua principal crítica à teoria da ação éa de privilegiar a relação entre o par"o quê?" e "por quê?"como modo de identificar qual ação é significante. 
Tal processo deve-se, também, a uma dicotomia primária na teoria da ação que distingue ação de acontecimento. É a partir dessa dicotomia que uma primeira configuração da ação se faz: no contraste com o movimento. Ação e movimento são de duas naturezas diferentes. Portanto, fazer não é acontecer, pois este se pressupõe observável, como movimento, como conhecimento empírico. Algo evidenciado no exemplo:

Os músculos do braço contraem-se, ele levanta o braço. Ao levantar o braço, fez sinal de que vai virar. Só o primeiro enunciado se refere a um acontecimento que ocorre na realidade, os outros dois designam uma acção, um nomeando-a, o outro, explicando-a pela sua intenção (RICOEUR, 1988, p. 34).

Com isso, a teoria da ação distingue ação humana do acontecimento a partir do "fazer chegar", relacionado ao primeiro, e do "chegar", ao segundo, sendo que entre um e outro há um abismo lógico. Relacionado a essa distinção também está a de motivo e causa. Enquanto o motivo de agir está implicado na noção da ação, ou seja, é interno à ação, a relação causa-efeito é externa. Paul Ricoeur é extremamente crítico quanto a essa dicotomia, visando uma possibilidade de que um motivo também seja uma causa.

Três observações importantes devem ser feitas para as análises subseqüentes, referente à ação nas artes visuais. A primeira se refere ao poder-fazer e ao saber-fazer do agente. Por poder-fazer entende-se a capacidade de ação, o poder de agir; o que cada agente pode fazer. Por saber-fazer entende-se um saber gerido mediante a ação em si, e não de um conhecimento empírico. Como observa Ricoeur (1988, p. 30): "O conhecimento sem observação e o raciocínio prático (...) apontam ambos para essa espécie de saber que não é um saber que, mas um saber como".

A segunda observação refere-se ao caráter público da ação. A inteligibilidade da ação é pública, a partir do momento que se pode compreender praticamente toda a rede conceitual. Há aqui uma inteligência prática, dado que o saber-fazer é um saber pela possibilidade de se ensinar a partir de um exemplo.

E, enfim, a terceira observação refere-se à passividade. $\mathrm{O}$ agente também é paciente; ou seja, age e também sofre conforme as circunstâncias. Considerando o caráter público da ação, Ricoeur afirma que "agir é sempre agir 'com' outros: a interação pode assumir a forma da cooperação, da competição ou da luta" (RICOEUR, 1994, p.89). 
Quanto à história da arte, o recorte tem como objetivo o meio artístico conhecido como performance art, que surge entre as décadas de 1960 e 70 e se fixa como uma das expressões artísticas de maior ascensão da arte contemporânea. A performance art pode ser considerada a primeira expressão ou gênero das artes visuais que tem sua pedra angular na ação. No entanto, anteriormente à sua ascensão, houve desenvolvimento e experimentações relacionadas à ação que possibilitaram seu surgimento.

Mais do que fazer uma retomada histórica da ação nas artes visuais, do seu aparecimento e desenvolvimento ${ }^{3}$, a preocupação aqui é delinear o momento em que a ação realmente tornou-se parte da obra de arte; isto é, objeto de significação artística, sendo entendida e usada pelo artista como tal e, posteriormente, compreendida como parte da obra de arte, senão a própria obra.

Dessa maneira, a análise da ação inicia-se a partir do estudo do artigo "Os Action Painters Norte-Americanos", do crítico de arte Harold Rosenberg, de 1952, em que o estudioso reflete sobre a nova pintura de sua época. Esse artigo possui dupla importância para essa análise: em primeiro lugar, demonstra o reconhecimento, compreensão e interpretação, por parte do crítico, da ação na obra desses artistas. Em segundo lugar, é uma produção teórica, que denota sedimentação da compreensão prática da ação como parte da obra de arte. É fato que o desenvolvimento teórico de Rosenberg sobre esses artistas não foi o único em sua época, nem mesmo foi o mais marcante referente à História da Arte, entretanto, indiscutivelmente, é o mais importante relacionado ao desenvolvimento da ação nas artes visuais.

A análise continua no estudo do happening, experimentação prática que surge a partir de uma geração de artistas posterior aos "action painters", e diretamente influenciado por estes. Como veremos, a compreensão da ação por esses artistas permitirá que ela seja definitivamente assimilada pelas artes visuais. Levando ao extremo o que já havia sido alcançado pela action painting, a ação como parte significante da obra de arte, esses artistas eliminam o objeto transformando a própria ação em obra de arte.

Do 'happening inaugural' ao que ficou conhecido popular e historicamente por happening, há uma mudança do tratamento e trabalho com a ação por parte dos artistas. A ideia de acontecimento é tomada como primordial de tal modo que os happenings se afastam da influência da action painting, tendo como principais características a anulação do artista e a inclusão do público na obra de arte. 
A conclusão deste trabalho será com a performance art. Essa surge diretamente ligada ao happening, no entanto, distancia-se deste ao abandonar suas principais características e pretensões, ao mesmo tempo em que retoma questões delineadas por Rosenberg sobre a action painting. Na performance art, a ação será tomada num sentido forte, relacionada diretamente ao agente que age no mundo e em direção ao outro.

\section{Action painting: a ação como componente significante da obra de arte}

Em 1952, o crítico de arte publicou o artigo 'Os Action Painters Norte-Americanos' refletindo sobre a nova pintura de sua época. Centrado na produção de artistas como De Kooning e Jackson Pollock, Rosenberg desenvolve em seu artigo uma reflexão teórica evidenciando como característica única e inovadora dessa produção artística a inclusão da ação na obra de arte final. Ou seja: a pintura torna-se um ato, sendo a ação de pintar e a pintura, indiscerníveis.

$\mathrm{O}$ artigo pode ser dividido em duas partes. Na primeira, Rosenberg praticamente esboça uma teoria da ação, em um sentido filosófico, a partir da produção artística contemporânea. A segunda parte refere-se a uma sociologia da arte e à crítica de arte. A segunda parte pressupõe a primeira.

Rosenberg inicia sua reflexão com a problemática da definição de um movimento como um termo geral que não dá conta das características individuais, mas que é, ao mesmo tempo, necessário para capturar o que há de essencial neles. A partir dessa aporia, sua reflexão desembarca na produção artística norte-americana que, logo após a Segunda Guerra Mundial, realizou todo tipo de estilo artístico europeu ${ }^{4}$, principalmente focado na arte abstrata.

Partindo de sua dúvida "Será isto a atualização habitual com as formas de arte européias por parte da América do Norte? Ou algo de novo estará sendo criado?" (ROSENBERG, 1974, p. 12), pontua a necessidade de uma definição e reflete sobre a produção da arte americana como revisita à pintura moderna e européia.

É ao final dessa pequena introdução que Rosenberg inicia sua teoria da ação. Ao levantar a questão de que a nova pintura norte-americana não se caracteriza como uma escola artística, pois para essa é necessário não somente "uma nova conscientização de pintura, como também de uma conscientização desta conscientização" e ainda que "a escola é o resul- 
tado da união da prática com a terminologia - telas diferentes são atingidas pelas mesmas palavras" (ROSENBERG, 1974, p. 12), Rosenberg pontua que nesse novo paradigma da pintura as palavras não pertencem à arte, mas aos artistas.

Apesar de ainda não ter iniciado sua tese sobre a ação, já traz a primeira questão relacionada à ação: o agente. Assim, Rosenberg detecta a rede conceitual da ação por um de seus conceitos-chave, indicando o agente como a pessoa do artista, ou seja, chama a atenção para a representatividade do "quem?" da ação, contrapondo-o a uma possível interpretação de um agente coletivo, a escola.

Logo a seguir, Rosenberg precisa a sua tese:

Em determinado instante, para um pintor norte-americano depois do outro, a tela começou a afigurar-se como uma arena na qual se age - mais do que um espaço no qual se reproduz, se reinventa, se analisa ou se 'expressa' um objeto, real ou imaginado. (ROSENBERG, 1974, p. 12-13.)

Tal estrato traça exatamente a mudança de paradigma da pintura por meio da ação. Esta, que sempre esteve relacionada ao momento da criação, da produção artística, transcende o limite em direção à obra de arte. Reproduzir, reinventar, analisar ou expressar são ações relacionadas ao momento anterior à obra de arte, e nunca parte desta. Afirmar que se age é colocar a ação em primeiro plano, inscrevê-la na pintura, fazer de ambos um só, e não uma ação e sua conseqüência.

E ele continua: "o que se destinava às telas não era um quadro, mas um acontecimento" (ROSENBERG, 1974, p. 13). $\mathrm{O}$ termo acontecimento nesse contexto merece uma atenção especial. O sentido empregado na frase é o de ato, é a da relação temporal da ação, o momento e não um observável, um objeto do acontecer. Aqui, o acontecimento não é o "quê?" da ação, mas o "quando?". Assim como a tela se transforma em arena no sentido do "onde?" da ação. O sentido de acontecimento está mais relacionado ao sentido empregado por Paul Ricoeur (1989, p. 186) ao definir "o discurso é o acontecimento da linguagem". Dessa maneira, o discurso possui quatro características que o fazem um acontecimento: realiza-se temporalmente e no presente; requer um sujeito, sempre remetendo ao seu locutor; refere-se sempre a um mundo; e direciona-se ao outro, o seu interlocutor. É principalmente a temporalidade que caracteriza o acontecimento de Rosenberg, não como um acontecimento fugidio, mas aquele que se caracterizaria 
como o "dito" da fala, ou, mais precisamente, "é a significação do acontecimento de fala, não o acontecimento enquanto acontecimento" (RICOEUR, 1989, p. 187).

Continuando com Rosenberg:

A nova pintura norte-americana não é arte 'pura', pois a expulsão do objeto não se verificou em consideração à estética. As maçãs não foram varridas da mesa a fim de sair de modo que nada obstruísse o caminho da ação de pintar. Neste gesticular com materiais, também se subordinou a estética. (ROSENBERG, 1974, p. 14)

Ao se referir à arte pura, aludindo ao surgimento da arte abstrata ou mesmo a "arte-pela-arte" do modernismo europeu, o crítico não só distancia a nova pintura da tradição moderna, como a classifica como base primitiva o campo da ação. Do mesmo modo que para Ricoeur o campo prático é prévio aos da ética, política e jurídica, para Rosenberg também se tornou prévio à estética. A ação não foi somente adicionada à pintura, como o foi com as colagens nos cubistas, ela foi inscrita diretamente na pintura através da ação de pintar, fazendo parte do seu âmago e tornando-se a priori da própria estética.

E, finalizando a parte referente à sua teoria da ação, Rosenberg afirma:

Uma pintura que seja um ato é inseparável da biografia do artista. Constitui ela em si mesma um 'momento' na mistura adulterada de sua vida - quer o 'momento' signifique os precisos minutos empregados em manchar a tela, quer signifique a duração total do drama lúcido desenrolado em linguagem simbólica. (ROSENBERG, 1974, p. 14)

Temos aqui um ponto final na sua teoria da ação, em concordância com a rede conceitual da ação em Ricoeur. A "biografia do artista" constata não só a atribuição direta da ação ao seu agente, mas também, em outro nível, a relação que o campo prático possui com o campo histórico. Isso também é reforçado devido à inserção clara da questão temporal relacionando pintura a momento, ou seja, o "quando" da ação.

A análise da continuação do artigo de Rosenberg foge do objetivo deste trabalho. O principal interesse aqui é a constituição da "teoria da ação" por parte do autor como reflexão de um novo paradigma na arte, e as conseqüências e influências que terão em práticas artísticas posteriores. A sua teoria da 
ação é toda construída sobre a relação artista-ação, direcionando-se à obra de arte. $\mathrm{E}$, como veremos, não somente $\mathrm{a}$ influência das obras dos artistas da action painting atingiu uma geração de artistas posteriores, mas o próprio desenvolvimento do crítico de arte encontrará reflexos ulteriores.

\section{Happening: a ação como um acontecimento natural}

O happening é uma prática artística que surge no final da década de 1950, nas artes visuais, e que se estende e se populariza pela década de 1960. Do trabalho inaugural que batizou essa prática com tal nome, há uma diferença com o que posteriormente foi considerado por happening, na sua forma mais popular. A característica principal dessa diferença encontra-se na relação artista e público.

No trabalho inaugural, 18 happenings em 6 partes de Allan Kaprow de 1959, encontra-se a intenção de participação do público na ação. E é a partir desse trabalho que todas as práticas artísticas baseadas na ação serão chamadas de happenings, apesar de muitos artistas não concordarem com o termo e aplicarem sua própria terminologia, como performance, event e aktion. Apesar da intenção da relação entre artista-público persistir, ela terá uma nova forma, mais radical, que se tornará a marca identificadora dos happenings, ao mesmo tempo em que ocorre a abertura para uma nova prática baseada na ação: a performance art.

Allan Kaprow não somente criou o happening, mas também o teorizou. Ele praticamente descreveu uma teleologia de seu processo de criação que encontra o happening como o fim do sistema. Ben Vautier, em seu texto "O Teatro Total", de 1963, o sintetiza bem desta maneira:

De acordo com o próprio Kaprow Seu procedimento foi: tela, depois tela e pintura, depois tela com objetos colados nela, depois tela e objetos suspensos, depois os objetos suspensos da tela encheram a galeria, depois os objetos foram postos em movimento, depois ele acrescentou gestos, pessoas e gritos, depois tudo saiu da Galeria de Arte para ser inserido numa Usina abandonada ou num Vale. (BEN VAUTIER, 2002, p. 105)

O artista organiza sua produção artística de modo teleológico5, iniciando na pintura e encontrando como fim o happening. O concatenamento de sua produção supõe uma 
certa evolução de caráter intencional, tendo o espaço e o público como fatores de organização de tal ordem. É desse modo que compreende o seu desenvolvimento, que sai da pintura tradicional para as assemblages ("tela com objeto colados nela" e "tela e objetos suspensos"), para se direcionar aos environments ("objetos suspensos da tela encheram a galeria"), para obras que possibilitavam uma interatividade maior dos visitantes ("objetos foram postos em movimento"), para assim chegar ao "18 happenings em seis partes" ("acrescentou gestos, pessoas e gritos) e ao que foi considerado happening em geral ("tudo saiu da Galeria de Arte para ser inserido numa Usina abandonada ou num Vale.").

Kaprow afirma que é precisamente no environment que a sua preocupação com o espaço se direcionará para o público, sendo essa a nova linha-guia para a criação. Chega mesmo a afirmar que "progressivamente, durante 1957 e 1958, isso me sugeriu a necessidade de dar mais responsabilidade ao espectador e continuei a oferecer-lhes cada vez mais, até chegar ao happening" (GLUSBERG, 1982, p. 32).

A necessidade de dar responsabilidade ao espectador é fundamental para o happening e marca a passagem do trabalho inaugural para o que se consolidou como tal. Naquele, o trabalho foi desenvolvido em um espaço construído, que possuía cadeiras para o público sentar-se, subdivisões e dentro de uma proposta prévia e marcada, seis artistas desenvolviam ações simples, leituras de textos, monólogos, produções de filmes, slides, música e pintura. Ao espectador foram dadas instruções que deveriam ser seguidas durante todo o trabalho. A proposta era a de vivência de um acontecimento simultâneo.

A responsabilidade dada ao espectador ainda era tímida, quase instrumental, em um sentido ético. Contudo, no sentido semântico aqui pretendido, a responsabilidade é atribuição. Independentemente do espectador ser instruído ou não, as suas ações fizeram parte de todo esse "acontecimento". Recorrendo à rede conceitual da ação, todos os agentes desempenharam suas ações dentro da proposta de Kaprow, que, de certo modo, foi o proponente das intenções e motivos para tal desenvolvimento. Conforme afirma Ricoeur (1988, p. 63) "atribuir uma acção a alguém é dizer que ele é o portador da intenção. Inversamente, a intenção leva a marca da pessoa". Tendo isso em vista, considera-se Allan Kaprow como o "quem?" da ação, pois é ele quem 'dá a marca' à ação e é ele quem atribui as mais diversas ações aos mais diversos agentes.

Deste modo, dá-se para afirmar que esse trabalho está ali- 
nhado à compreensão da ação de Rosenberg sobre a action painting, da relação agente e ação. Porém, a própria compreensão que Kaprow tinha do trabalho de Jackson Pollock também é de extremo interesse. Em 1957, ele publicou o texto "O legado de Jackson Pollock" em que faz uma análise da importância desse para a sua geração de artistas. No momento em que reflete sobre o ato de pintar, a similaridade com o artigo de Rosenberg é precisa, contudo, e indo além, Kaprow (2006, p. 39) constata que "Ele criou algumas pinturas magníficas. Mas também destruiu a pintura". Estando no centro da destruição a própria ação.

Ao fim da reflexão sobre o ato de pintar, a forma e o espaço e todas as suas inovações em Pollock, Kaprow se questiona sobre o que resta ser feito. Da opção de continuar a produzir pinturas a partir da estética desse artista, Kaprow lança a alternativa da desistência da pintura. Assim, como real legado de Pollock, está o

(...) momento em que temos de passar a nos preocupar com o espaço e os objetos da nossa vida cotidiana (...) não satisfeitos com a sugestão, por meio da pintura, de nossos outros sentidos, devemos utilizar a substância específica da visão, do som, dos movimentos, das pessoas, dos odores, do tato. (KAPROW, 2006, p.44)

E continua:

Objetos de todos os tipos são materiais para a nova arte: tinta, cadeiras, comida, luzes elétricas e néon, fumaça, água, meias velhas, um cachorro, filmes, mil outras coisas que serão descobertas pela geração atual de artistas. (KAPROW, 2006, p.44)

Descreveu, assim, dois anos antes, o que foi o primeiro e inaugural happening.

Como vimos, há como ponto central a necessidade de proporcionar mais responsabilidade ao espectador fazê-lo participar da obra de arte como parte integrante. $\mathrm{O}$ artista proporcionou isso por meio de instruções precisas, assim como todo o trabalho, com suas marcações, ritmos e ensaios. Praticamente tudo isso será abandonado no sentido que o happening ficou mais popular. De uma ação controlada e proposta pelo artista, direcionada à participação do público, o happening se tornaria uma ação junto ao espectador e, em sua forma mais radical, sem diferenciação entre artista e espectador, mesmo que utopicamente. $\mathrm{O}$ novo paradigma do happening possui 
sua coluna vertebral nas ações e no direcionamento, muitas vezes quase ideológicos, do grupo Fluxus. A este, a influência do Zen Budismo e de John Cage são essenciais para se compreender como entendiam e propunham seus happenings.

Com John Cage, se dá a absorção de questões que explora em sua peça musical 4'33", composta pelos ruídos proporcionados pela platéia no intervalo em que se abre e fecha o teclado do piano. Como Arthur Danto afirma:

(...) muitos dos seus primeiros seguidores (do grupo Fluxus) eram membros do seminário de composição experimental de Cage na New School. Mas eles não estavam interessados simplesmente na disjunção entre ruído e música. (DANTO, 2002, p. 25)

O real interesse do Fluxus estaria na transposição entre os limites entre arte e mundo concreto. Algo que Cage já indicara em suas experimentações e pesquisas musicais, afirmando que

Os próximos passos eram sociais, e ainda estão sendo dados. Primeiro, precisamos de uma música na qual não só sons sejam simplesmente sons, mas na qual pessoas sejam simplesmente pessoas, ou seja, não sujeitas a leis estabelecidas por qualquer uma delas, mesmo se esta for "o compositor" ou "o maestro". Finalmente, precisamos de uma música que não mais estimule a participação do público, pois nela a divisão entre músicos e público não mais existe: é uma música feita por todos.

O que é necessário é uma música que não precise de ensaio. (DANTO, 2002, p. 24)

Em tal citação, Cage já caracterizava o que viria a ser um happening. Trocando a música pela ação, encontra-se a matriz do happening executado e popularizado pelo Fluxus: uma ação em que as pessoas sejam simplesmente pessoas, não sujeitas a leis como a de um artista-propositor, uma ação feita por todos e que não precise de ensaio.

Da influência do Zen Budismo, do qual Cage era um estudioso e entusiasta, o Fluxus absorveu um interesse especial pelo comum, pelo simples, pelo cotidiano, de forma que "a crença de que a consciência mais elevada poderia ser alcançada mediante a mais comum das atividades". (DANTO, 2002, p. 28) Desse modo, as ações no happening tendiam à simplicidade, como uma transposição da idéia de ready-made, de Marcel Duchamp, para a ação. Como pontua Arthur Danto, uma ação ready-made possui certas limitações: 
Um objeto ready-made tem de ser de certa forma ultracomum, um objeto sem nada de extraordinário. Uma ação "ready-made" deveria, igualmente, ser o tipo de ação que pudesse ser executada de maneira simples e fácil por qualquer pessoa, a qualquer hora - uma ação que não precisasse de nenhum tipo de treinamento específico ou da aquisição de habilidade alguma em particular - os tipos de ação que seriam bons exemplos do Zen. (DANTO, 2002, p. 28.)

Dessa maneira, o happening em seu formato mais popular caracteriza-se por ações simples, isto é, propostas simples para que o público pudesse participar em contraposição à ação mais complexa do happening inicial. A diferença em relação ao público se fez em possibilitar uma participação mais aberta desse, enquanto na primeira a participação estava relacionada diretamente às instruções dos artistas.

O Fluxus com o seu ideal de coletividade acabou influenciando e caracterizando o happening, pensado como um termo e uma prática mais ampla, indo além dos artistas que participavam desse grupo. Jorge Glusberg nos traz uma declaração assinada por diversos artistas de happenings ao redor do mundo:

Articula sonhos e atitudes coletivas. Não é abstrato nem figurativo, não é trágico nem cômico. Renova-se em cada ocasião. Toda pessoa presente a um happening participa dele. É o fim da noção de atores e público. Num happening, pode-se mudar de "estado" à vontade. Cada um no seu tempo e ritmo. Já não existe mais uma "só direção" como no teatro ou no museu, nem mais feras atrás das grades, como no zoológico. (GLUSBERG, 1982, p. 32.)

Essa declaração de 1965 deixa claro o conceito de happening alinhado às aspirações do grupo Fluxus. A orientação a "atitudes coletivas", assim como ao "fim da noção de atores e público", são marcas precisas do ideal Fluxus. Mas há outra marca precisa que foi absorvida pelo happening: a de "qualidades impessoais de um acontecimento simplesmente natural" (DANTO, 2002, p. 30).

Essa afirmação é de extremo interesse neste momento. Ela está conjugada diretamente com a intenção de uma coletividade e a extinção do limite entre artista e público por meio da pretensa eliminação do próprio agente subjetivo. A relação arte e vida, antes tematizada por Rosenberg sobre 
a action painting, é tomada como ideal no happening. A questão nem é mais a supressão do objeto, como Allan Kaprow expressou em seu texto sobre Pollock, o passo dado agora é no sentido da vida, tomando o público como objeto, como alvo de interesse.

Foi na dissociação entre artista e público almejada pelos artistas do happening que a questão da coletividade entrou em jogo. Na busca da supressão desse limite, o happening direcionou-se a propostas de ações coletivas, com características simples, de modo que possibilitasse a participação de todos igualmente. Contudo, nesse mesmo movimento, tenderam a anulação do agente.

Como pondera Paul Ricoeur (1988, p. 63), no caso de ações complexas, assim como ações coletivas, "como atribuir a cada um a sua parte?". A atribuição, nesse caso, torna-se distribuição. De modo algum há um agente coletivo, mas diversos agentes que operam coletivamente, sendo possível distribuir as devidas responsabilidades. E, como o filósofo afirma: "a pesquisa do autor é uma investigação terminável, que acaba com a determinação do agente” (RICOEUR, 1991, p. 117).

Portanto, mesmo considerando uma ação coletiva, a atribuição a um ou mais agentes sempre é possível, por não ser uma investigação interminável. O que se deve considerar no happening é a pretensão de se tornar um acontecimento natural de qualidade impessoal. Relembrando a dicotomia da teoria da ação, o happening é almejado no sentido contrário em que os filósofos analíticos consideravam especificar a ação humana, isto é, o happening tendia ao "chegar" e não ao "fazer chegar".

Isso se tornou um limite mais conceitual do que prático. Os artistas dos happenings tinham como intenção a destituição do limite entre artista e público o que se tornou pretensão no momento em que se direcionaram à coletividade visando um acontecimento natural impessoal. É, pois, a partir desse limite ideológico, que surge a performance art. No âmago da produção do happening que a ação, como produção de significação artística, alcança um novo paradigma. Isso ocorre quando alguns artistas ultrapassam esse limite, abandonando a pretensão de um acontecimento impessoal e assumindo a si mesmos como agentes da ação.

Como veremos, a impessoalidade natural é substituída pelo caráter pessoal do artista. Portanto, é no contraste com o happening, e na retomada das considerações sobre a action painting, que poderemos analisar melhor o estatuto da ação na performance art. 


\section{Performance art: a ação como obra}

A performance art surge durante a década de 1960, mas se caracteriza e se fortalece como meio artístico a partir da década de 1970. Ela tem influência direta da compreensão da ação na action painting, sendo ao mesmo tempo uma metamorfose do happening. O seu surgimento está relacionado a este, e é a partir da experimentação dos artistas que essa expressão começa a se caracterizar como uma arte da ação. Será na comparação com esses meios anteriores, entre suas concordâncias e discordâncias, assim como a uma análise da ação na performance art, que será possível verificar como a ação transforma-se em obra na performance art.

Quanto a action painting, a performance art herdou a compreensão do papel da ação na obra de arte. Ao inscrevê-la na obra de arte, os artistas colocavam a si mesmos, as suas biografias e tudo relacionado à ação nela. A performance art, do mesmo modo, manteve essa mesma característica configurando-se como uma radicalização mais extrema que o próprio happening, ao fortalecer a relação entre agente e ação. Enquanto no happening a ação tinha pretensão de gerar um acontecimento natural, anulando o agente, na performance a ação transforma-se na expressão do poder-fazer do artista, elevando a significação da ação à significação como arte.

Ainda sobre o happening, a performance art deu continuidade a sua principal conquista: a aniquilação do objeto e transformação da ação em obra de arte. Entretanto, exatamente onde o happening se limitou, a performance art se expandiu. Isto é, a intenção de um acontecimento natural por meio de uma ação coletiva impessoal tornou-se seu próprio limite, ao mesmo tempo que abriu a possibilidade do surgimento da performance art. Deste modo podemos afirmar que a característica principal da performance art - em contraste com o happening - é a relação agente-ação.

Contudo, as questões relacionadas à arte e vida e à inclusão do público na obra de arte não são totalmente abandonadas pela performance art. Da parte da relação arte e vida, já Rosenberg afirmou que a action painting alcançara esse patamar de relação a partir da inclusão da ação na pintura. Poderíamos dizer que temos aqui uma via de mão única, no sentido de inclusão da vida na arte. Com o happening, ao destituir o objeto da arte, radicalizou essa relação por meio de uma via de mão dupla, ou seja, buscou no cotidiano, como esfera da vida, as ações que se tornaram artística, assim como, no mesmo 
movimento, buscou com essas ações invadir o cotidiano. Se Rosenberg falara que a tela transformou-se numa arena para os pintores, com o happening o cotidiano virou tema e arena.

Já com a performance art, essa relação de arte e vida não é colocada em questão pois é assumida como pressuposto de sua existência. É a relação dialética que gera a performance art como possibilidade dupla, tanto na arte como na vida, por meio de um fio condutor único: a ação. A ação da performance art é inicialmente ação do ser humano no mundo e o seu significado é extraído a partir das mais diversas significações que tais ações já possuem na esfera da vida. Se a ação é objeto da ética, dos estudos jurídicos e da política, na performance $a r t$, a ação também é objeto da estética. No entanto, não como objeto exclusivo, mas sim como componente junto a outros campos citados. Ou seja, cada obra de performance art não explora somente questões estéticas, mas também questões de ordem jurídica, ética, moral e política. No momento em que o artista faz uma obra de performance art, além de explorar a estética da ação, ele coloca em jogo questões éticas e morais sobre a ação, morais, também, sobre o uso do corpo, questões políticas da relação com o público, questões jurídicas da relação de sua ação com a sociedade etc. Tais questões fogem do domínio da arte, mas fazem parte do domínio da vida.

Quanto ao público, ele continua como participante da obra de performance art, contudo, não como pretendido pelo happening. Retomando Paul Ricoeur, a ação é interação. Não se restringe somente a agir, mas, também, a sofrer uma ação. $O$ agente é também paciente e agir é sempre agir com os outros, ou seja, faz parte da ação também a passividade. Esta não está somente no outro que sofre ou interage com a ação, mas também está na relação agente-ação. Ricoeur (1991, p. 82) é enfático ao afirmar que há uma implicação lógica entre desejar e fazer, e que "na nossa linguagem, ter vontadee fazer pertencem-se mutuamente". E assim, “é segundo uma cadeia lógica de implicação que passamos de 'ter vontade' a 'ter vontade de fazer', a 'tentar fazer' e finalmente, a 'fazer'. Há uma distância entre ter vontade e agir, que é mediada pela passividade.

Assim, na performance art o público não é mais aquele corpo coletivo convidado a fazer parte com nos happenings. Ele é, na realidade, o "outro" da ação. Esse corpo coletivo fora substituído por pessoas que interagem, seja como pacientes ou agentes. A possibilidade de interação aberta em uma obra de performance art é a mesma possibilidade de interação nas ações que fazemos no mundo. À vista disso, o público não é "convidado" ou "instruído" a fazer parte, mas ele já é parte no momento em que está pre- 
sente. Inclusive, a relação artista e público é mais ética, no sentido de que as pessoas que formam o público possuem liberdade para escolher a sua interação com o artista, seja ativa, alterando a ação do artista com suas próprias ações, ou passiva, que encontra uma variada gama desde o "assistir à performance" ao "ignorar a ação". No entanto, sempre é exigido do público, e sem coação, uma escolha de como se relacionar com uma obra de performance art, seja como agente ou paciente. Por conseguinte, podemos afirmar que a performance art não só se diferencia do happening, mas o supera na relação com o público por permitir uma relação de alteridade.

Essa superação também é na questão da ação mesma. Se no happening tendeu a utilizar ações simples, baseadas no cotidiano, na performance art, por outro lado, direcionou-se a uma ação considerada mais complexa. O conceito de ações de base de Arthur Danto, sempre muito bem recordado por Paul Ricoeur, será útil para ajudar nessa distinção. As ações de base ou ações básicas são as ações primárias que podemos fazer. São as ações imediatas, de primeira ordem, não causadas, isto é, "ações que nós sabemos fazer e que fazemos, com efeito, sem ter de fazer uma outra em vista de fazer o que fazemos; tais são, grosso modo, os gestos, as posturas, as ações corporais elementares"(RICOEUR, 1991, p. 181).

Assim, as ações de base são as ações imediatas que possibilitam as ações mediatas. Em certo sentido, o happening direcionou-se a explorar ações de base, como exemplares do cotidiano. Contudo, a performance art direcionou-se a ações complexas, ou seja, na concatenação de uma cadeia de ações, do modo que exige por parte do artista a escolha, deliberação e hierarquização de suas ações. À performance art não se destinou somente uma ação, mas diversas ações, caracterizada pelo poder de agir, pensado nas ações de base, e pelo poder que o agente tem de deliberar sobre quais ações serão feitas e como serão.

Com isso, a performance art traz a relação complexa que as ações possuem no mundo para a arte. Tudo que é possível em termos de ações no mundo, o é na performance art. O elo dessa relação dialética é o par artista-ação. É no artista que repousa a questão do "eu posso" da ação, é em seu poder como agente que repousa a deliberação de qual ação tomar, ou mesmo não tomar. Inclusive o corpo do artista, considerado por nós como particular de base da performance art, está relacionado a esse "eu posso". A posição central do corpo na performance art é inovadora, enquanto na action painting o corpo foi abstraído pelo próprio objeto da pintura. No happening, o corpo foi suprimido pelo seu 
caráter impessoal e, como vemos com Paul Ricoeur (1991, p. 159) "a impessoalidade do acontecimento marca antes de qualquer coisa a neutralização do corpo próprio”. É, pois, na performance art que o corpo é assumido como corpo próprio, ou seja, 'meu corpo'. Ainda com Ricoeur:

Uma vez que o corpo próprio constitui um dos componentes da minha totalidade, a confrontação mais radical deve confrontar as duas perspectivas sobre o corpo, o corpo como meu e o corpo como um corpo entre os corpos. (RICOEUR, 1991, p.59)

A performance art só não é considerada a arte do corpo ${ }^{6}$, pois ela supera a própria questão do corpo. Na semântica é possível observar essa diferença, conforme os conceitos de particulares de base: corpo e pessoa. Relembrando o argumento, Strawson nos traz, referente à identificação, a separação de particular de base corpo e particular de base pessoa. Um é irredutível ao outro. No entanto, ao particular de base corpo são atribuídos predicados físicos, enquanto ao particular de base pessoa são atribuídos predicados físicos e psicológicos. Ou seja, é ao particular de base pessoa que se atribuem duas séries de predicados a uma mesma coisa. Nesse sentido que Paul Ricoeur (1991, p. 85) afirma que essa "atribuição única resulta que a ação é ao mesmo tempo certa configuração de movimentos físicos e um cumprimento suscetível de ser interpretado em função das razões de agir que o explicam". Podemos objetar que a arte do corpo está diretamente relacionada ao particular de base corpo, assim como a performance art está para o particular de base pessoa.

Desenvolvemos até o momento a questão da ação na performance art tendo em vista o que agregou e contrastou com a action painting e o happening. Agora faz-se necessário uma reflexão da ação exclusiva que determine considerá-la como obra da performance art. Como afirmado anteriormente, a ela estão relacionadas diretamente as ações complexas, mais do que uma ação, uma cadeia de ações. Portanto, adicionamos mais uma configuração de ação complexa. Para Ricoeur:

É preciso entender bem mais que um prolongamento das conexões entre os segmentos de ação postos em forma pela gramática das frases de ação. É preciso mostrar uma hierarquia de unidades práxicas que, cada uma a seu modo, comporte um princípio de organização específica integrando uma diversidade de conexões lógicas. (RICOEUR, 1991, p.181) 
A essa hierarquia de unidades que Ricoeur se refere como práticas, imprimindo um sentido forte ao termo. Assim, por práticas ele dá como exemplo "as profissões, as artes, a medicina etc" (RICOEUR, 1991, p. 181). Segundo o filósofo, o concatenamento das ações como descritas pela teoria da ação é insuficiente para a abordagem das práticas, sendo necessário outro modelo, um modelo misto segundo o autor, que coordene os segmentos de causalidade física e os segmentos intencionais. Desse modo:

Obteríamos longas cadeias de ação nas quais a passagem do ponto de vista sistêmico [causalidade física] ao ponto de vista teleológico [segmentos intencionais] seria assegurada em cada ponto da cadeia pelo fato de que o agente é capaz de considerar os efeitos de causalidade como circunstâncias de decisão, enquanto que em volta os resultados desejados ou não-desejados das ações intencionais tornam-se novos estados de coisas conduzindo a novas cadeias causais. (RICOEUR, 1991, p. 182)

Conforme o filósofo, é essa união entre causalidade física e intencionalidade que configura as ações complexas e longas que são as práticas. E, no interior dessas práticas, além das relações sistêmica e teleológica, há uma relação de subordinação entre ações parciais a uma ação total. Considerando isso, a performance art se configura como uma prática com essa estrutura da ação complexa. Fala-se a ação em uma obra de performance art, mas esta pode conter as mais diversas ações. E, de outro modo, a performance art também se configura como uma prática que possibilita a absorção de outras práticas, sendo possível no interior de sua obra as mais diversas práticas. É, pois, assim, que a ação, considerada como ação total, permite aos artistas que desenvolvam as diversas ações e práticas, produzindo os mais diversos trabalhos, mas tendo todos unicidade que possibilite reconhecê-los como uma obra da performance art.

São, portanto, as ações, num sentido forte e complexo tomadas como um conjunto que agregue causalidade física e segmentos intencionais e que, encadeadas a partir do artista, configuram algo como uma obra de performance art. Tais ações são absorvidas do mundo, da experiência vivencial, cotidiana, ordinária, mundana. O repertório de ações em uma obra de performance art é o mesmo repertório que o agente encontra no campo prático e no mundo, com os seus devidos sentidos e significações. Surge a necessidade 
de se questionar o que distingue as ações na obra da performance art a das ações fora delas.

Retoma-se, assim, a questão do discurso para iniciar esta reflexão. Paul Ricoeur ([1989], p. 111) afirma que é nele que se apresenta um traço primitivo de distanciação, o qual coloca "sob o título da dialéctica do acontecimento e da significação". O discurso é o acontecimento da linguagem, possuindo quatro características: realiza-se temporalmente e no presente, está diretamente ligado ao sujeito que o profere, sempre se refere a um mundo e se direciona a outros mundos, ou seja, dirige-se a um interlocutor. É, então, nessa dialética entre acontecimento e significação que nasce a obra. Desta maneira, afirma que "se todo discurso é efectuado como acontecimento, todo discurso é compreendido como significação" (RICOEUR, [1989], p. 112). Não é o acontecimento do discurso que compreendemos, mas a significação que ele proporciona. Aqui se configura a distância entre o dizer (temporal, presente e fugidio) com o dito (a fixação do dizer). É o dito entendido como exteriorização intencional que a escrita inscreve, fixa e não o acontecimento do dizer. Ou seja, o que inscrevemos é "a significação do acontecimento de fala, não o acontecimento enquanto acontecimento" (RICOEUR, 1989, p. 187). Adiciona-se, aqui, a caracterização do discurso como obra, que o autor define três traços: 1 . Composição, referente a uma seqüência mais longa que a frase e que se constitui como uma totalidade finita e fechada. 2. Pertença a um gênero literário, como narração, ensaio etc. 3. Estilo individual, configuração única ligada ao locutor.

Assim como Paul Ricoeur faz um paralelo entre discurso e ação, prolongamos esse paralelo à performance art. Portanto, é, também, a dialética entre acontecimento e significação que gera a obra de performance art. Assim como no discurso, as quatro características as são também na performance art, ou seja, a obra se realiza temporalmente e no presente, está diretamente ligada ao artista, ela se refere a um mundo e está direcionada a interlocução com outros mundos, isto é, as pessoas presentes que configuram um público plural. Para nós, adicionamos que a performance art se realiza no mundo, assim como o discurso, no sentido que não é criado um mundo ficcional, da mesma maneira que o artista não representa uma ação, simplesmente age.

Quanto à distanciação entre acontecimento e significação, na performance art o sentido que é produzido enquanto o artista age, produz uma "marca social". Há dois níveis de fixação, 
uma de primeira ordem, que está relacionada diretamente ao interlocutor da performance art, ou seja, o público presente. E a fixação de segunda ordem, que é a dos registros de obras de performance art, seja de forma narrativa, fotografia ou mesmo gravadas em vídeo. $\mathrm{O}$ que as define de segunda ordem é exatamente a impossibilidade da temporalidade presente. Todas essas passam por algum tipo de filtro que extingue ou codifica a característica básica da performance art.

E a analogia dos traços que fazem do discurso uma obra são extremamente ricos para compreender as ações de um artista como uma obra de performance art. Contudo, pretendemos seguir outra ordem, que será mais rica para a análise. Quanto ao estilo individual, claramente está relacionado ao artista, sendo que é esse traço que possibilita a compreensão das mais diversas ações relacionadas aos mais diversos artistas como uma obra de performance art. O "estilo individual" do artista está diretamente relacionado ao par agente-ação, ao seu agir, a como agir e deliberar no agir. Quanto à composição, está relacionada não somente ao agir, mas à criação de uma performance art. A ação possui um sentido que está relacionada diretamente ao ponto de vista sistêmico (causalidade física) e ao ponto de vista teleológico (segmento intencional), configurando-se como o sentido proposto pelo artista. Ele compõe uma ou mais ações complexas e/ou práticas que desenvolve em um determinado espaço e tempo, mas que, ao mesmo tempo, possuem uma totalidade. São tanto suas ações nesse período quanto o conjunto total que é fixado como significação da obra de performance art.

Por fim, o traço de pertencimento a um gênero abre certo problema. Apesar de o presente trabalho estar focado nas artes visuais, levanta-se a possibilidade de considerar por gênero outros gêneros artísticos, como teatro e dança, que também apresentam e exploram a performance art como meio. No entanto, descartamos essa possibilidade pois, dentro desta perspectiva, a literatura também se apresenta como um gênero. $\mathrm{O}$ traço gênero, definido por Paul Ricoeur, está dentro da literatura e tem como configurações "as características que cada discurso individual possui e que se caracteriza como um gênero". Nesse sentido, poderíamos elevar a performance art a um patamar equivalente ao de dança, teatro e artes visuais. Desta maneira, as características comuns que as mais diversas obras de performance art apresentam podem constituir como os gêneros. Alinhado a isso, estaria a divisão temática que 
a historiadora Roselee Goldberg faz em seus livros, ou seja, como gêneros apresenta-se teatro, dança, vida real, política, corpo e identidades. Particularmente, pendemos a considerar essa última opção.

Mas sendo essa uma questão aberta, e que foge ao presente trabalho, chamamos especial atenção à narração como gênero, de tal maneira que seria possível afirmar que há uma estrutura narrativa na performance art. A narração não estaria relacionada a um possível traço ficcional que pudesse ser encontrado na performance art, pelo contrário, está relacionada ao próprio campo da ação, a uma relação narrativa que temos com o mundo, e mesmo a relação do campo da ação com o campo da história. Para Paul Ricoeur em Tempo e Narrativa (Tomo I), existe essa relação com a sua tríplice mimese, sendo a mimese I o momento da pré-configuração da ação, a mimese II o momento de configuração da ação por meio da intriga (o muthos grego) e a mimese III o momento de reconfiguração da ação junto ao leitor, no caso da performance art, junto ao público. Deste modo, Ricoeur é preciso ao afirmar que uma compreensão narrativa encontra ancoradouro na compreensão prática que temos do mundo, e a sua análise engloba tanto a narrativa de ficção como a histórica. Contudo, é em O Si-Mesmo como um Outro que trará a narrativa como mediador entre a descrição e a prescrição da ação. $O$ que nos interessa aqui é precisamente essa mediação da narrativa que, na performance art, possibilita ao artista criar uma performance conceitualmente e apresentá-la como um projeto, assim como é a que permite o público, posteriormente à performance executada, narrar o que foi presenciado. Entre o caráter futuro do projeto e o caráter passado do público, encontra-se a configuração de uma trama complexa de ações que o artista executa no tempo presente.

Concluindo, é na performance art que a ação assume o status de obra, mantendo sua configuração complexa obtida por meio da dialética entre acontecimento e significação, assim como da dialética arte e vida. A obra da performance art está relacionada diretamente ao artista, que emprega no tempo presente as suas ações, assimilando práticas, interagindo no mundo e em interlocução com outras pessoas que formam o público. E é, dessa maneira que podemos afirmar que a performance art se configura como arte da ação complexa, ou simplesmente: arte das ações. 
1. Artigo apresentado como monografia para obtenção do título de especialista em Estética e Filosofia da Arte pela Universidade Federal do Paraná. Este artigo foi revisado e reeditado para a presente publicação.

2. Assumiremos o termo teoria da ação (em itálico) para se referir especificadamente a teoria da ação desenvolvida pelos filósofos analíticos de língua inglesa.

3. Referente às primeiras manifestações relacionadas à ação, consultar Roselee Goldberg, Performance art: Do futurismo ao presente e J. Glusberg - A arte da performance.

4. Para Rosenberg, a palavra estilo possui uma força extremamente formal, relacionada a questões formais e pictóricas, no caso, herdadas da arte européia. Assim, por estilo artístico europeu, Rosenberg se refere a movimentos como o impressionismo, cubismo, abstracionismo, surrealismo, etc.. A dúvida que permeira esse momento de seu artigo é se há uma produção original norte-americana ou simplesmente reproduções e adaptações do que já foi produzido em anos anteriores na Europa.

5. Por teleologia, queremos marcar a organização que Kaprow faz de sua produção artística que terá como fim o happening. Também queremos marcar a orientação que Paul Ricoeur dá a teleologia no que concerne a sua filosofia da ação, como sendo o modo de organização da intenção da ação em contraposição da organização sistemática da causalidade do acontecimento. Iremos retomar esse conceito sobre o ponto de vista teleológico da ação no próximo capítulo, referente a performance art.

6. A Arte do Corpo ou Body Art surgiu durante a década de 196o e é considerada uma influência prévia à performance art, conforme Jorge Glusberg. Ainda hoje, o termo body art é utilizado e tem-se debatido se performance art é body art. De nossa parte, consideramos body art aquelas que têm o corpo como tema, podendo ou não envolver a performance art ou utilizar esta como "suporte" ou meio de expressão. Dessa maneira, a body art seria uma corrente artística que utiliza os mais diversos meios como a performance art, a pintura, a fotografia, etc.

\section{Referências bibliográficas}

ARGAN, Giulio Carlo. Arte moderna: do iluminismo aos movimentos contemporâneos. Tradução de: Bottmann, D.; Carotti, F. São Paulo: Companhia das Letra, 1992.

COHEN, Renato. Performance como linguagem: criação de um tempo-espaço de experimentação. São Paulo: Perspectiva, 1989.

DANTO, Arthur C. Acciones Básicas. Tradução de: J. A. Robles. Ciudad Universitaria - México: Universidad Nacional Atónoma de México - Instituto de Investigaciones Filosóficas, 1981. (Cuadernos de Crítica, 10).

O mundo como armazém: Fluxus e filosofia. In: HENDRICKS, Jon. O que é Fluxus? O que não é! O Porquê. Detroit: The Gilbert and Lilá Silverman Fluxus Collection Foundation, 2002.

JONES, Amelia; WARR, Tracey. The Artist's body. New York: Phaidon, 2002.

GLUSBERG, Jorge. A arte da performance. Tradução de: Rena- 
to Cohen. São Paulo: Perspectiva, 1987.

GOLDBERG, Roselee. A arte da performance: do futurismo ao presente. Tradução de: Jefferson Luiz Camargo. São Paulo: Martins Fontes, 2006.

GOLDBERG, Roselee. Performance: Live art since the 6os. Singapore: Thames and Hudson, 1998.

HILL, Marcos; ROLLA, Marco Paulo (org.). MIP - Manifestação Internacional de Performance. Belo Horizonte: CEIA, 2005.

KAPROW, Allan. O legado de Jackson Pollock. Tradução de: Pedro Süsseskind. In: COTRIM, Cecília; Ferreira, Glória (Org.). Escritos de artistas: anos 6o/70. Rio de Janeiro: Jorge Zahar, 2006.

MELIM, Regina. Performance nas artes visuais. Rio de Janeiro: Jorge Zahar, 2008.

RICOEUR, Paul. Do texto à acção: ensaios de hermenêutica II. Tradução de: Alcino Cartaxo e Maria José Sarabando. Porto: Rés, [1989]. . O discurso da acção. Tradução de: Artur Morão. Lisboa: Edições 70, 1988. . O si-mesmo como um outro. Tradução de: Lucy Moreira Cesar. Campinas: Papirus, 1991. - Tempo e Narrativa: tomo 1. Tradução de: Constança Marcondes Cesar. Campinas: Papirus, 1994.

ROSENBERG, Harold. A tradição do novo. Tradução de: Cesar Tozzi. São Paulo: Perspectiva, 1974.

SÁNCHEZ, Alfredo Martínez. La filosofia de la acción de Paul Ricoeur. Isegoría, Madrid, n. 22, p. 207-227, 2000.

STRAWSON, P. F. Individuos. Tradução de: Alfonso García Suárez; Luis M. Valdés Villanueva. Madrid: Taurus Humanidades, 1989.

Recebido em: 27/07/10

Aceito em: 10/o1/11

\section{FERNANDO CESAR RIBEIRO \\ difernandoribeiro@gmail.com}

Especialista em Estética e Filosofia da Arte pela UFPR em 2010. Bacharel em Artes Visuais pela UTP - Universidade Tuiuti do Paraná em 2002. Estuda e pesquisa a performance art há 10 anos, com desenvolvimento teórico e prático. Participou do MIP - Manifestação Internacional de Performance em 2003 e da exposição histórica O corpo na Cidade: performance em Curitiba. 